J. Lake Sci. (湖泊科学), 2013, 25(3): 445-454

http: //www. jlakes.org. E-mail: jlakes@niglas.ac.cn

(C) 2013 by Journal of Lake Sciences

\title{
汉江上游安康东段全新世古洪水沉积学与水文学研究"
}

\author{
许 洁, 黄春长, 庞奖励, 查小春, 周亚利, 周 亮 \\ (陕西师范大学旅游与环境学院,西安 710062)
}

\begin{abstract}
摘 要: 通过沿汉江上游河谷深人的考察, 在安康东段发现了典型的古洪水滞流沉积剖面. 通过采集样品、实验分析, 确 定它们是古洪水在高水位滞流环境当中的悬移质沉积物. 根据地层对比、OSL 测年和相关文化层年代, 确定它们分别记录 了发生在 BL + AL 与 YD 事件转折阶段 (12500 a B. P. ) 的古洪水事件和发生在 1000-900 a B. P. (1000-1100AD), 即北 宋后期的洪水事件. 根据古洪水 SWD 的高程恢复其洪峰水位,结合相关参数,利用面积比降法计算恢复流量. 结果表明在 万年尺度, 汉江上游古洪水洪峰流量介于 $35970 \sim 47400 \mathrm{~m}^{3} / \mathrm{s}$ 之间. 同时, 利用 2010 年大洪水洪痕恢复计算洪峰流量, 对 古洪水洪峰流量计算结果进行了验证. 进而结合历史洪水和观测洪水数据, 获得了汉江上游万年尺度洪水洪峰流量与频 率关系. 这为汉江上游的水利水电和交通工程建设以及沿岸城镇防洪减灾提供了基础性数据.
\end{abstract}

关键词: 汉江上游;古洪水;万年尺度;全新世;滞流沉积物

\section{Sedimentological and hydrological studies of the palaeoflood events in the Ankang east section in the upper reaches of the Hanjiang River}

\author{
XU Jie, HUANG Chunchang, PANG Jiangli, ZHA Xiaochun, ZHOU Yali \& ZHOU Liang \\ (College of Tourism and Environment Sciences, Shanxi Normal University, Xi' an 710062, P. R. China)
}

Abstract: Through field investigation in the upper reaches of the Hanjiang River, palaeoflood slackwater deposits were found in the Ankang east section. The results of sedimentary analyses indicate that these slackwater deposits are typical suspended sediment load deposits of floodwater. By stratigraphic correlation, OSL dating and archaeological dating, the palaeoflood events represented by SWD1 were dated to be between the palaeo-climatic stage of BL + AL and Younger Dryas Event ( YD, 12500 a B. P. ). During this period, the upper reaches of the Hanjiang River experienced a series of rainstorm flood events. The pollen records from the Southern Lake of Shennongjia area in the upper reaches of the Hanjiang River also suggest that this was the period of high climatic fluctuation frequency. The SWD2 in the east Ankang section appears in the bottom of well-developed modern topsoil layer. At the edges of Ankang-Yunxian river terrace, the set of SWD layers often cover the culture layer which belongs the Northern Song Dynasty when climate condition was very unstable, and serious drought and flood disaster occurred based upon historical records. The palaeoflood events recorded by SWD2 were dated to be AD $1000-1100$ (i. e. $1000-1100$ a). Based on the reconstruction of palaeoflood peak stages and the hydrological parameters for the river section, the palaeoflood peak discharges were between 35970 and $47400 \mathrm{~m}^{3} / \mathrm{s}$. These values were checked with the the reconstruction of the flood in 2010 based on the stage indicator identified during the fieldwork, and the results showed the Ankang hydrologic station measured data error is only 4.52\% . Thus we believe that the peak flow calculation for the upper reaches of the Hanjiang River canyon ancient flood is reasonably accurate, the calculation results are reliable. Based on our calculation from sedimentological perspective the historical flood investigation results were combined with observed flood series, with a large value of the complete sequence of frequency calculation method, and the upper reaches of Hanjiang River in the eastern part of Ankang section million-years-scale peak flow and frequency relations were established. The results provide data for establishing flood discharge - frequency relationship at a 10000-year time-scale in the upper reaches of the Hanjiang River. This is very critic and will provides key data for hydraulic engineering and flood control in the upper reaches of the Hanjiang River and the flood control and disaster mitigation engineering construction along the waterfront towns in the

* 国家自然科学基金重点项目(41030637)、国家社科基金重点项目(11AZS009)和中央高校基本科研业务费专项基 金项目 (GK201101002) 联合资助. 2012-06-06 收稿;2012-10-18 收修改稿. 许洁,女, 1987 年生,硕士研究生; E-mail:xujie_423@163.com. 
region, except the scientific value of the Hanjiang River's regional changes in climate and hydrology in response to the global climate changes.

Keywords: Hanjiang River; palaeoflood; 10000-year time-scale; Holocene; slackwater deposits

古洪水水文学是国际全球变化科学领域的前沿之一, 主要研究发生在全新世未被人类直接观察记录的 洪水事件 ${ }^{[1]}$, 采用地貌学、沉积学和水文学等方法来恢复全新世特大洪水的水位和流量, 提供万年尺度的大 洪水水文学数据, 有助于深刻理解河流水文系统对于全球变化的响应规律, 并能为各类工程的洪水设计提 供可靠依据 ${ }^{[2-3]}$. 古洪水研究的关键主要是重建河流古水文要素. 美国 Baker 教授认为古洪水滞流沉积层和 古洪水水位标志物是恢复古洪水洪峰水位的重要依据 ${ }^{[4]}$. 杨达源教授等通过对古洪水滞流沉积层的研究, 认为滞流沉积物尖灭点高程与古洪水洪峰水位十分接近 ${ }^{[5]}$. 目前美国、西班牙、印度、法国、日本、澳大利亚 等国家都已经在古洪水研究方面取得了显著成果 ${ }^{[4-6]}$. 我国学者也在黄河、长江、淮河、海河的某些河段进行 了古洪水研究,并取得了一定的科研成果 ${ }^{[7-10]}$. 黄春长教授等系统地对泾河、洛河、渭河以及黄河晋陕峡谷某 些主要河段,开展了古洪水沉积学、年代学和水文学方面的研究,并系统地总结提出了全新世古洪水滞流沉 积物的基本鉴别特征 ${ }^{[11-17]}$. 本文主要是在汉江干流安康河段考察的基础上, 沿河谷古洪水滞流沉积物进行 沉积学分析,并对其进行古洪水水文学恢复研究,获得了万年尺度特大洪水水文资料.

\section{1 研究区环境与研究河段概况}

汉江是长江北侧最大的支流, 发源于米仓山西端陕西省宁强县潘冢山, 全长 $1577 \mathrm{~km}$, 流域面积 $15.9 \times 10^{4} \mathrm{~km}^{2}$, 平 均海拔 $2000 \mathrm{~m}$ 左右, 天然落差 $1964 \mathrm{~m}$. 全流域多年平均降水量 $873 \mathrm{~mm}$, 多年平均径流量 $517 \times 10^{8} \mathrm{~m}^{3}$, 年平均含 沙量 $2.5 \mathrm{~kg} / \mathrm{m}^{3}$, 年输沙量 $1.3 \times 10^{8} \mathrm{t}$. 流域处于北亚热带的北部, 气候温和, 雨量充沛, 森林覆盖面积高达 $62 \%$. 汉江可分为上、中、下三段,丹江口以上为上游, 长约 $925 \mathrm{~km}$, 集水面积 $9.52 \times 10^{4} \mathrm{~km}^{2}$. 汉江自西向东 穿行于秦岭与大巴山之间, 河谷常与岩层走向斜交, 平均比降为 $0.6 \%$, 河道大多为蜿蜒曲折的峡谷, 在汉中 和安康形成河谷盆地. 汉江上游是国家“南水北调” 中线工程的水源区 (图 1). 丹江口至钟祥为汉江中游, 长 约 $270 \mathrm{~km}$, 平均比降 $0.19 \%$, 集水面积 $4.68 \times 10^{4} \mathrm{~km}^{2}$, 汉江自西北向东南,穿行于低山和丘陵岗地之间, 流 速减缓. 钟祥以下为下游, 长约 $382 \mathrm{~km}$, 平均比降 $0.09 \%$, 集水面积 $1.7 \times 10^{4} \mathrm{~km}^{2}$, 汉江缓慢流动在汉江平原 地区.

汉江上游干流安康水文站以上长度为 $528 \mathrm{~km}$, 控制流域面积 $3.57 \times 10^{4} \mathrm{~km}^{2}$, 多年平均流量 $568.78 \mathrm{~m}^{3} / \mathrm{s}$, 年平均径流总量 $179.37 \times 10^{8} \mathrm{~m}^{3}$. 安康自 1935 年开始有水文观测资料(其中 1939-1942 年、1949 年中断), 实测最大洪峰流量 $31000 \mathrm{~m}^{3} / \mathrm{s}\left(1983\right.$ 年 7 月 31 日), 最小为 $1800 \mathrm{~m}^{3} / \mathrm{s}\left(1941\right.$ 年) ${ }^{[18]}$. 历史调查最大洪水洪峰 流量约 $36000 \mathrm{~m}^{3} / \mathrm{s}$ (明代万历十一年, 公元 1583 年).

\section{2 地层剖面特征与研究方法}

\section{1 研究剖面特征}

在汉江上游流域山间盆地、河流阶地常常发育着黄土一古土壤系列. 前人通过对典型黄土剖面的研究, 确认其为风成黄土堆积, 建立了黄土一古土壤与气候变化序列, 在多处还发现有旧石器时代人类文化遗

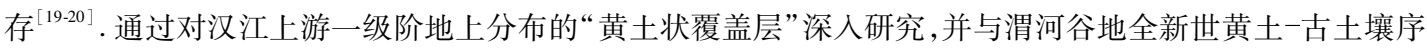
列对比, 表明这些 “黄土状覆盖层” 是晚更新世以来沙尘暴在区内连续堆积的结果, 具有 $\mathrm{TS}^{-} \mathrm{L}_{0}-\mathrm{S}_{0}-\mathrm{L}_{\mathrm{t}}-\mathrm{L}_{1}-\mathrm{AD}$ 土壤一地层学剖面构型, 并准确判析其成因和形成时代 ${ }^{[21]}$.

在此基础上,通过对汉江上游河谷的实地考察, 在多个河段发现含有全新世古洪水滞流沉积层的全新 世土壤与沉积物剖面. 本文选择安康东段进行重点研究 (图 2). 其中 LSC-A 沉积剖面位于安康盆地东端立 石村汉江第一级河流阶地 $\left(\mathrm{T}_{1}\right)$ 前沿位置, 其中阶地的基岩基座高出平水位 $12 \mathrm{~m}$, 河床相卵石层和沙层构成 的具有二元结构的冲积物厚度 $3 \sim 5 \mathrm{~m}$, 更上部为含有钻结核的风成黄土和古土壤层覆盖层, 厚度 $4 \sim 5 \mathrm{~m}$. 该 地形面高于汉江平水位 $20 \sim 25 \mathrm{~m}$, 土壤侵蚀严重, 故黄土质覆盖层顶部的全新世中晚期段已经缺失.

在详细观察研究的基础上, 结合土壤学、沉积学和地层学方法, 对阶地上部覆盖层汉江安康东段 LSC-A 


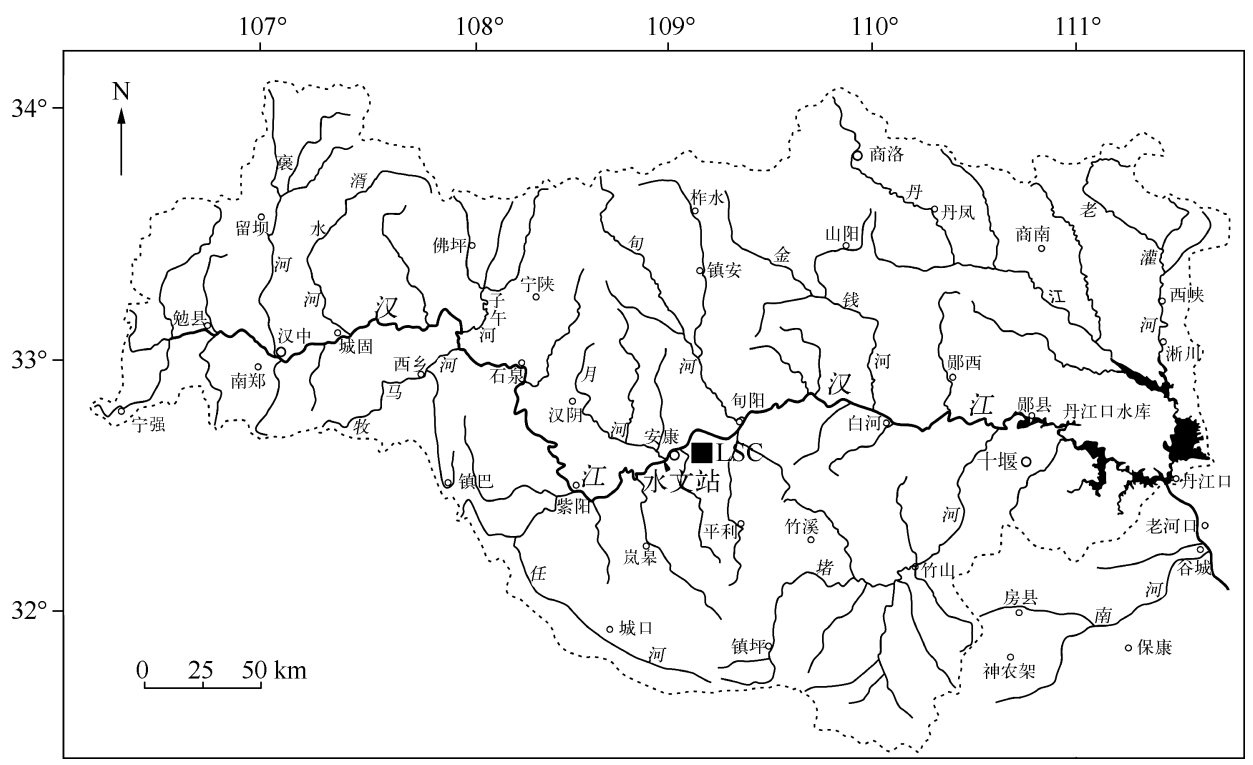

图 1 汉江上游流域水系

Fig. 1 Sketch of the stream system in the upper reaches of the Hanjiang River 剖面(图 3)进行了详细的地层划分: (1)0 $100 \mathrm{~cm}$, 浊红棕色, 黏土质粉砂质地, 棱块 状构造, 为典型的全新世中期古土壤层 $\left(\mathrm{S}_{0}\right)$ (黄褐土)下部; (2) $100 \sim 350 \mathrm{~cm}$, 全新 世早期黄土质过渡层 $\left(\mathrm{L}_{\mathrm{t}}\right)$ 和马兰黄土 $\left(\mathrm{L}_{1}\right)$ 上部, 含有坚直的钙结核; (3) $350 \sim 370 \mathrm{~cm}$, 浊黄橙色, 细沙质粉砂质地, 具有波状或者 倾斜状层理, 一组共有 3 层, 是最典型的古 洪水滞流沉积物 (SWD1 $)^{[17]}$; (4) 370 $450 \mathrm{~cm}$, 浊棕色, 黄土 $\left(\mathrm{L}_{1}\right)$ 下部, 有较弱程 度成壤; (5) $450 \mathrm{~cm}$ 以下 (未见底).

在汉江安康东段 LSC-B 剖面(图 3), 全 新世中上部黄土土壤层次完整清晰. 0 $150 \mathrm{~cm}$, 为浊红棕色, 黏土质粉砂, 具有典型 团粒结构, 多含虹蚓粪团和植物根系, 为发 育较好的现代表土层, 其中在 $75 \sim 130 \mathrm{~cm}$ 发现有 1 组 4 层灰白色沙质粉砂层

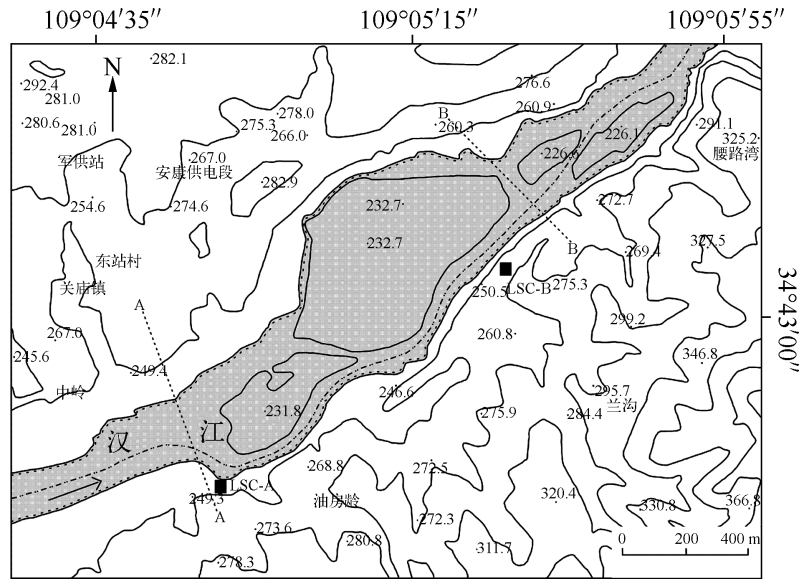

图 2 汉江上游安康东段地形

Fig. 2 The topography of the Ankang east section in the upper reaches of the Hanjiang River $(\mathrm{SWD} 2) .150 \mathrm{~cm}$ 以下为全新世晚期黄土 $\left(\mathrm{L}_{0}\right)$ 和古土壤 $\mathrm{S}_{0}$ (未见底).

\section{2 研究方法与采样点}

在野外考察获得汉江古洪水沉积物地层学和沉积学资料基础上, 对该河段进行了详细的观测, 获得了 一系列水文学参数数据. 同时, 在沉积物剖面采取 2 个古洪水 SWD 沉积学样品和 6 个光释光样品. 沉积学样 品深度分别为安康 LSC-A 剖面在 355 365 cm 处, 安康 LSC-B 剖面在 $80 \sim 90 \mathrm{~cm}$ 处. 光释光样品的采样是将 地层清理出垂直的新鲜面后, 选取不同沉积层位, 用直径 $5 \mathrm{~cm}$ 不锈钢管垂直打进剖面, 取出后立即用铝箔纸 和黑色塑料带密封, 以免曝光和水分散失. 共采取 OSL 样品 6 个, 安康 LSC-A 剖面 3 个样品和安康 LSC-B 剖 面 3 个样品, 分别为 $0.725 \mathrm{~m} \mathrm{LSC}-\mathrm{B}-01 、 0.925 \mathrm{~m} \mathrm{LSC}-\mathrm{B}-02 、 1.275 \mathrm{~m} \mathrm{LSC}-\mathrm{B}-03 、 3.425 \mathrm{~m} \mathrm{LSC}-\mathrm{A}-01 、 3.575 \mathrm{~m}$ 


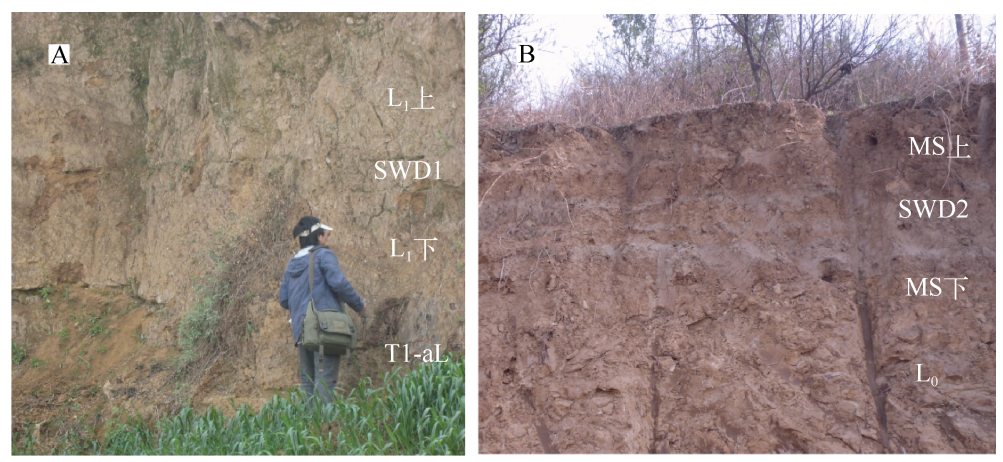

图 3 汉江上游 LSC-A 和 LSC-B 地层剖面

Fig. 3 LSC-A and LSC-B profiles in the upper reaches of the Hanjiang River

LSC-A-02、3. $775 \mathrm{~m}$ LSC-A-03. 我们还调查测量了 2010 年 7 月 18 日特大洪水(安康水库人库流量 $25500 \mathrm{~m}^{3} / \mathrm{s}$, 出库流量 $21700 \mathrm{~m}^{3} / \mathrm{s}$ ) 的洪痕及其高程, 采集其滞流沉积物样品, 以便进行沉积学和水文学对比分析和验证 研究,保证研究成果的可靠性.

将野外采得的沉积物样品在实验室内自然风干后, 对样品进行前处理, 并进行磁化率、粒度成分、砂 级颗粒 $(>0.1 \mathrm{~mm})$ 等的分析测试以及 OSL 测年. 具体方法如下: 磁化率采用英国 Bartington 公司生产的 MS-2B 型磁化率仪测量, 方法为称取研磨后粒径 $<2 \mathrm{~mm}$ 的风干土样 $10 \mathrm{~g}$ (精确至 $0.0001 \mathrm{~g}$ ), 装人无磁性 塑料盒进行测量, 每个样品测量 3 次, 取平均值. 粒度分析是在样品中加人 $10 \%$ HCl 以去除有机质和次生 $\mathrm{CaCO}_{3}$, 再加人适量 $\left(\mathrm{NaPO}_{3}\right)_{6}$ 充分分散后, 用英国 Malvern 公司生产的 Mastersizer-S 型激光粒度仪进行测 定. 每个样品平行测定 3 份, 取平均值. OSL 测年实验在陕西师范大学 RS/OSL 实验室完成, 采用单片再生 剂量法, 用丹麦生产的 RIS TL/OSL2DA215 仪测量, 释光信号通过 9235QB15 光电倍增管检测, 滤光片 为 $\mathrm{U} 340$.

\section{3 结果与讨论}

\section{1 古洪水事件的沉积学特征}

粒度分析是研究沉积物性质和成因的最基本手段之一. 粒度成分对于指示沉积物的物质来源、搬运介 质和动力、沉积环境及其风化改造程度等都具有十分重要的意义 ${ }^{[22-24]}$. 因此,粒度分析常作为鉴别古洪水滞 流沉积物的主要指标. 汉江上游安康东段 LSC 地点古洪水滞流沉积层的粒度成分数据及粒度参数值见表 1 . 可以看出古洪水 SWD 主要由粗粉砂、细砂和细粉组成, 黏粒含量很少. 因此将古洪水 SWD1 确定为粉砂质 细砂, 将 SWD2 确定为细砂质粉砂. 2010 年现代洪水 SWD 的性质与 SWD2 完全相同, 属于细砂质粉砂. 粒度 参数中, 标准离差 $(\sigma)$ 反应沉积物粒度的分选程度, 即颗粒大小的均匀性, 可以反映出沉积物搬运过程中的 动力条件以及次生风化改造作用的强度 ${ }^{[25]}$. 汉江上游安康东段古洪水 SWD 的 $\sigma$ 分别为 $1.95 、 1.72$, 表明其 分选性较好. 分选系数 $(\mathrm{S})$ 表示沉积物的分选性, 可以进一步反映沉积物搬运沉积动力条件和沉积环境. 安 康东段古洪水 SWD 分选系数分别为 $1.47 、 1.11$, 分选性较好. 偏态系数 (SK) 可量度颗粒自然分布频率的对 称程度, 并且表明平均值和中位数的相对位置. 安康东段古洪水 SWD 的 SK 为 $0.19 、 0.06$, 偏态均表现为正 偏, 主峰出现在粗粉砂和细砂段. 峰态 $(\mathrm{Kg})$ 可以衡量粒度频率曲线的尖锐程度, 即度量粒度分布的中部与两 尾端的展形之比. 安康东段古洪水 SWD 的 Kg 分别为 $0.86 、 1.11$, 分布曲线峰态中等 ${ }^{[9]}$. 这些指标说明它们 是典型的河流洪水悬移质沉积物.

粒度自然分布频率曲线则直观地表现出 SWD 沉积物的上述特征 (图 4), 可以看出古洪水滞流沉积层沉 积物 SWD1 呈现双峰型, 主峰偏向于细粒段,在细粉砂段出现一个次级峰. 这可能是因为 SWD1 沉积时代较 早,沉积之后的风化成壤作用改造影响. SWD2 近似成正态分布, 主峰突出在粗粉砂段. 其形态与 2010 年现 代洪水沉积 SWD 的粒度分布更加接近, 显示出其分选性更好. 
表 1 汉江立石村 (LSC) 古洪水与现代洪水沉积物粒度与磁化率分析结果

Tab. 1 Grain-size analysis and magnetic susceptibility of the palaeoflood and modern flood SWD at the LSC site in the upper reaches of the Hanjiang River

\begin{tabular}{lccccccccccc}
\hline 样品名称 & $\begin{array}{c}<0.002 / \\
(\mathrm{mm}, \%)\end{array}$ & $\begin{array}{c}0.002 \sim 0.016 / \\
(\mathrm{mm}, \%)\end{array}$ & $\begin{array}{c}0.016 \sim 0.063 / \\
(\mathrm{mm}, \%)\end{array}$ & $\begin{array}{c}>0.063 / \\
(\mathrm{mm}, \%)\end{array}$ & $\begin{array}{c}\mathrm{Md} / \\
\mu \mathrm{m}\end{array}$ & $\begin{array}{c}\mathrm{Mz} / \\
\mu \mathrm{m}\end{array}$ & $\begin{array}{c}\sigma / \\
\varphi\end{array}$ & $\begin{array}{c}\mathrm{SK} / \\
\varphi\end{array}$ & $\begin{array}{c}\mathrm{Kg} / \\
\varphi\end{array}$ & $\begin{array}{c}\mathrm{S} / \\
\varphi\end{array}$ & $\begin{array}{c}\text { 磁化率/ } \\
\left(\times 10^{-8} \mathrm{~m}^{3} / \mathrm{kg}\right)\end{array}$ \\
\hline LSC-SWD2 & 2.73 & 20.26 & 44.84 & 32.17 & 36.57 & 53.30 & 1.72 & 0.06 & 1.11 & 1.11 & 72.5 \\
LSC-SWD1 & 2.93 & 25.42 & 31.27 & 40.37 & 43.62 & 64.21 & 1.95 & 0.19 & 0.86 & 1.47 & 47.3 \\
2010-SWD & 2.03 & 17.69 & 44.49 & 35.78 & 45.09 & 53.77 & 1.55 & 0.25 & 1.09 & 0.99 & 51.7 \\
\hline
\end{tabular}

磁化率是沉积物中铁磁性矿物含量的间接指示, 磁 化率的高低可以反映沉积物堆积之后风化成壤作用影响 的强弱 ${ }^{[9,26-28]}$. 汉江上游安康东段古洪水 SWD 的磁化率 值都较低, 介于 $47 \times 10^{-8} \sim 73 \times 10^{-8} \mathrm{~m}^{3} / \mathrm{kg}$ 之间, 古洪水 SWD2 比现代洪水 SWD 的磁化率值稍大, 这可能是由于 沉积之后风化成壤作用改造所致 (表 1 ).

综上所述, 在野外仔细观察古洪水 SWD 特征的基础 上, 结合实验室沉积学指标表明汉江上游安康东段 LSC 剖面中古洪水沉积物, 具有河流悬移质沉积物特征, 为典 型的古洪水滞流沉积物. 它们是汉江上游古洪水事件的 直接记录, 为古洪水水文学的恢复研究提供了物质基础.

\subsection{OSL 测年结果}

安康东段河谷 LSC 地点 6 个光释光样品, 基本控制 两个剖面所夹古洪水滞流沉积层的关键层位. 而且汉江

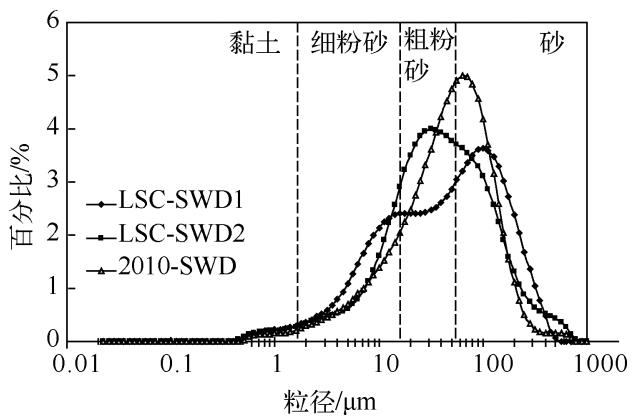

图 4 汉江上游立石村 (LSC) 地点古洪水和 现代洪水 SWD 粒度自然分布频率曲线

Fig. 4 Grain-size distribution frequency of the palaeoflood and modern flood SWD at the LSC site in the upper reaches of the Hanjiang River 上游 LSC 剖面地层关系清楚, 其地层年代可与汉江上游流域和渭河河谷的多个剖面进行对比. 根据沉积物 宏观特征, 识别出 LSC-A 剖面所记录的 SWD1 出现在 $350 \sim 370 \mathrm{~cm}$ 深度, 被夹在马兰黄土层之中 (图 5), 结

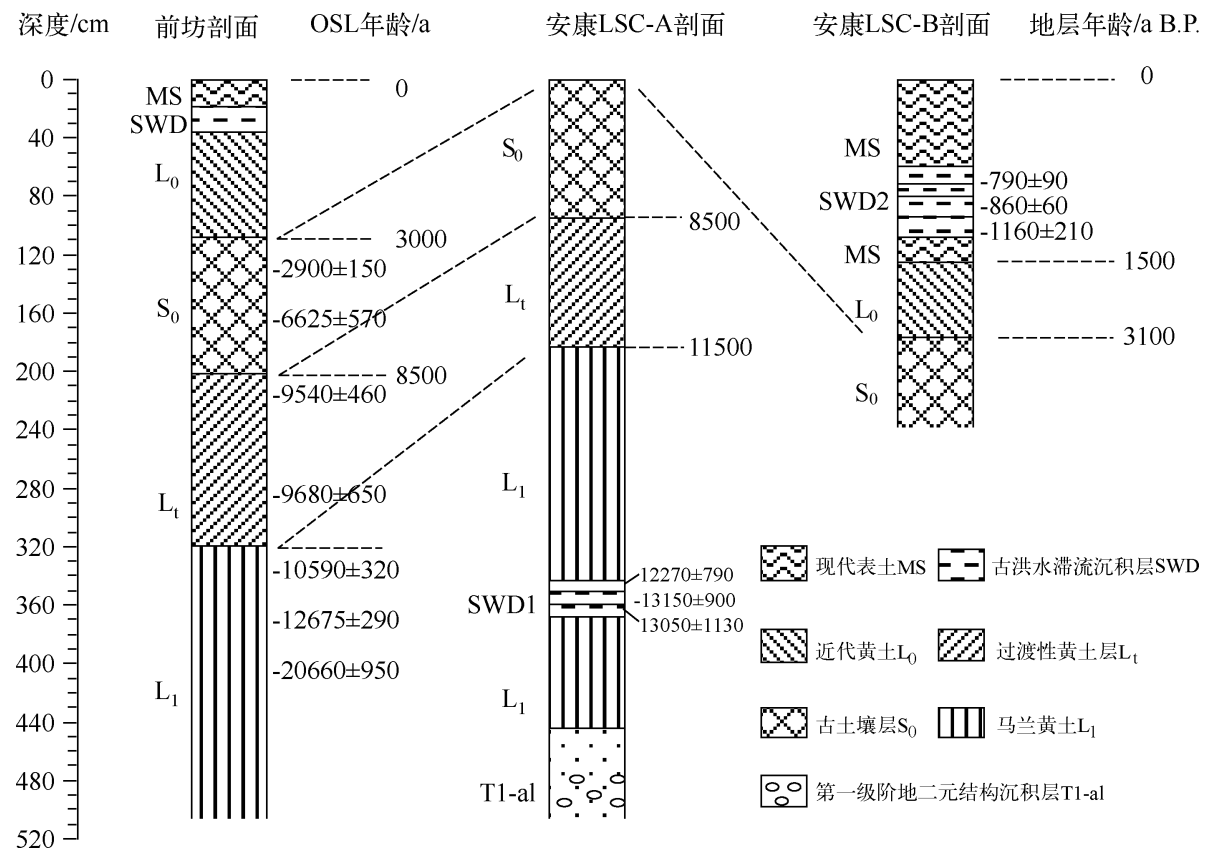

图 5 汉江上游 LSC-A 和 LSC-B 地层剖面图及 OSL 测年数据

Fig. 5 OSL age of the palaeoflood SWD from the LSC-A and LSC-B profile in the upper reaches of the Hanjiang River 
合沿汉江上游多个地点地层对比分析 ${ }^{[21]}$, 确定该期古洪水事件发生在 $20660-11500$ a B. P. 之间的某个时 段. LSC-A 剖面 SWD1 上下界的光释光年龄分别为 $12270 \pm 790 、 13050 \pm 1130$ a B. P., 而采自 SWD1 中部样 品的光释光年龄为 $13150 \pm 900 \mathrm{a}$ B. P. , 其光释光年龄比其上下层 2 个样品的年代略高, 这可能是由于古洪 水沉积样品晒退更为不彻底所致. 结合沉积地层对比和光释光测年结果分析, 可以确证 LSC-A 剖面所记录 SWD1 的发生年代介于 13150-12270 a B. P. 之间,所以认为 SWD1 记录了发生在晚冰期时代 (Late Glacial) 的 BL + AL (Bolling + Allerod Interstadial) 向着 YD(Younger Dryas) 转折的阶段. 这个转折事件的具体年代为 12500 a B. P. ${ }^{[29-30]}$.

全新世 LSC-B 剖面中, 75 130 cm 深度有 1 组 4 个极为典型的古洪水滞流沉积单层( SWD2), 它们插人全 新世晚期现代表土层 (MS) 之中( 图 3), 表明该期古洪水事件发生在 1500 a B. P. 以来的某个时段 ${ }^{[32]}$. SWD2 上 界和下界的释光年龄分别为 $790 \pm 90 、 1160 \pm 210$ a B. P. , 而取自 SWD2 中部的年龄为 $860 \pm 60$ a B. P. , 但由于释光 样品采样钢管直径为 $5 \mathrm{~cm}$, 故采集于 SWD 界线之上样品的 OSL 年龄值会比真实古洪水 SWD 发生年龄偏 小, 界线之下样品 OSL 年龄值则相对偏大. 由此,SWD2 的发生年代可较为准确地判定为 $1000-900$ a B. P. 之间, 即这期古洪水为北宋后期发生的洪水事件. 根据前人对于历史文献的整理研究, 也肯定了这是我国历 史上一个主要的气候恶化转折、洪水频发的时期 ${ }^{[31]}$.

\section{4 古洪水水文学研究}

在确定了古洪水事件之后, 洪峰水位的恢复主要依赖于古洪水滞流沉积层所在位置的高程关系. 杨达 源和谢悦波教授等 ${ }^{[5,10]}$ 认为古洪水滞流沉积层尖灭点高程, 可以很好地指示古洪水的洪峰水位, 其误差较 小. 经过野外观察, 该段河槽为基岩, 河道顺直稳定, 在全新世并未发生明显变化, 根据国内外关于古洪水研 究的基本原理, 即利用古洪水水文学方法恢复全新世古洪水洪峰水位和洪峰流量的地貌学依据是, 全新世 一万年以来基岩河槽受到河流下切造成的不同时期河床比降变化非常小,在计算时几乎不予考虑 ${ }^{[4,6]}$. 故根 据汉江上游安康东段 LSC 地点沉积记录, 结合汉江河槽水文特点, 选择 A-A 断面作为全新世之前晚冰期的 古洪水事件的水文恢复断面, B - B 断面作为全新世晚期北宋后期古洪水事件的水文恢复断面 (图 2). 这两 个断面的形态和各种水位高程关系见图 6. 对于河槽断面形态测量观察获得有关水文参数见表 2 .
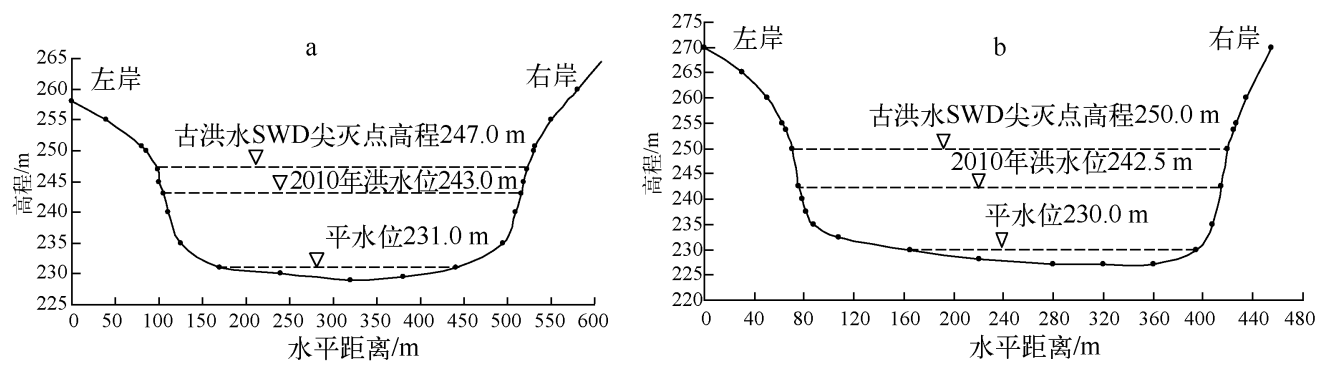

图 6 汉江上游立石村段 (LSC) 古洪水 $\mathrm{A}-\mathrm{A}(\mathrm{a})$ 和 $\mathrm{B}-\mathrm{B}(\mathrm{b})$ 过流断面图

Fig. 6 Cross-section A - A (a) and B-B (b) palaeoflood at the LSC site in the upper reaches of the Hanjiang River

当古洪水洪峰水位确定之后,古洪水洪峰流量的计算,则基本类似于历史调查洪水推求洪峰流量, 故其 计算方法较多. 根据本文选择的断面河槽和参数特点,采用最常用的面积一比降法来计算恢复古洪水洪峰流 量 ${ }^{[32]}$, 计算公式为:

$$
Q=\frac{1}{n} A \cdot R^{\frac{2}{3}} \cdot S^{\frac{1}{2}}
$$

式中, $Q$ 为洪峰流量 $\left(\mathrm{m}^{3} / \mathrm{s}\right), n$ 为河道糙率系数, $A$ 为过水面积 $\left(\mathrm{m}^{2}\right), R$ 为水力半径 $(\mathrm{m}), S$ 为水面比降.

在本研究中水面比降 $S$ 以河床比降代替, 在野外先用高精度 GPS 配合红外测距仪实地测量, 然后结合 
1: 10000 地形图中水面高程点进行校正, 确定汉江上游安康东段的比降为 $1.1 \%$. 许多研究表明, 河道䊁率的 选择对洪水洪峰流量计算的误差影响较大,䊁率系数变化 0.005 可导致推算的流量值相差 $25 \%$. 这足见糙 率系数选择准确十分重要 ${ }^{[8,10,33]}$. 汉江上游在全新世时期的基岩河槽变化很小,结合该河段的地表特征: 河 岸两则为基岩, 河底为沙卵石组成, 间有大漂石, 底坡尚均匀, 床面不太平整, 根据《水力学》中糙率表所描述 天然河道的特征和标准,糙率 $n$ 中值选取 0.035 . 并上下浮动 0.001 计算作为参考体系 ${ }^{[34]}$.

根据以上计算公式及其在研究河段确定的相关水文参数,结合两期古洪水的水位和行洪断面面积等, 推算出相应的古洪水洪峰流量 (表 2), 结果可知汉江上游安康东段在万年尺度特大洪水的洪峰流量介于 $35970 \sim 47400 \mathrm{~m}^{3} / \mathrm{s}$ 之间.

在同一河段调查得到的 2010 年 7 月 18 日大洪水的洪痕水位,我们采用同样的方法和参数,推算出其洪 峰流量为 $22680 \mathrm{~m}^{3} / \mathrm{s}$, 与实测洪峰流量误差为 $4.52 \%$, 这表明对古洪水水文恢复计算的结果可靠 (表 2 ).

表 2 汉江上游立石村 (LSC) 河段全新世古洪水和现代洪水水文恢复计算成果

Tab. 2 Results of palaeoflood and modern flood hydrological reconstruction in the LSC reach in the upper reaches of the Hanjiang River

\begin{tabular}{cccccccccc}
\hline 洪水期次 & \multirow{2}{*}{ 洪峰水位 $/ \mathrm{m}$} & 水面宽 $/ \mathrm{m}$ & 水深 $/ \mathrm{m}$ & 比降 $S$ & 䊁率 $n$ & $\begin{array}{c}\text { 断面面积 } \\
A / \mathrm{m}^{2}\end{array}$ & $\begin{array}{c}\text { 湿周 } \\
L / \mathrm{m}\end{array}$ & $\begin{array}{c}\text { 水力半径 } \\
R / \mathrm{m}\end{array}$ & $\begin{array}{c}\text { 洪峰流量 } \\
Q /\left(\mathrm{m}^{3} / \mathrm{s}\right)\end{array}$ \\
\hline SWD2 & 250.00 & 350.00 & 23 & 0.0011 & 0.035 & 6986.25 & 364.72 & 19.16 & 47400 \\
SWD1 & 247.00 & 424.00 & 18 & 0.0011 & 0.035 & 6387.00 & 440.88 & 14.49 & 35970 \\
2010 & 243.00 & 410.00 & 14 & 0.0011 & 0.035 & 4721.00 & 413.57 & 11.42 & 22680 \\
\hline
\end{tabular}

有了古洪水水文学研究成果, 就可以结合汉江安康水文站历史洪水和实测洪水数据,进一步分析万年 尺度洪峰流量与频率关系. 本文采用 “含有特大值的不完整序列频率分析” 方法 ${ }^{[10,32]}$, 作出汉江上游安康东 段万年尺度洪峰流量与频率关系图 (图 7). 这就使得汉江上游百年一遇, 千年一遇、万年一遇洪水洪峰流量 的推求, 由外延法转变为内插法, 从而能够获得比较准确的基础性数据. 这就从根本上保证了汉江上游各类 水利枢纽、交通和防洪工程的洪水设计更加可靠.

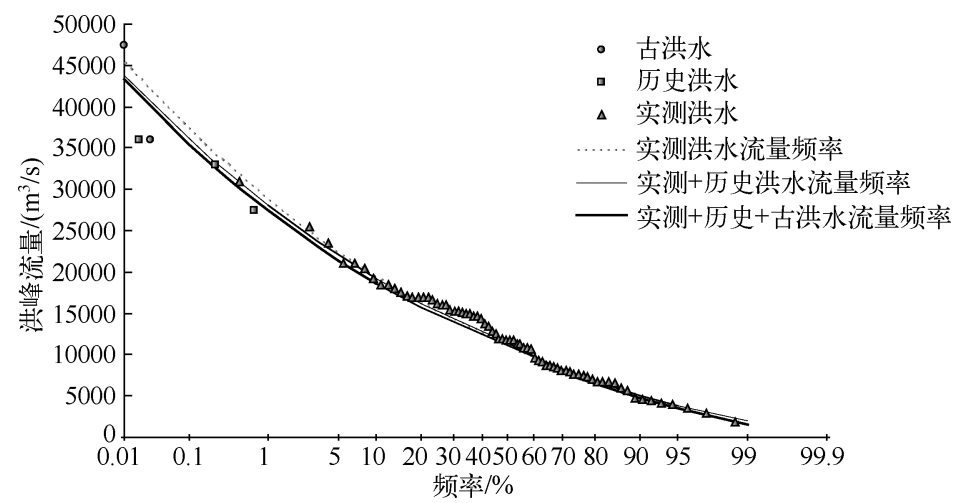

图 7 汉江上游安康东段万年尺度洪水洪峰流量与频率曲线

Fig. 7 Flood peak discharge-frequency relationship established with a combination of gauged flood, historical flood and palaeoflood data in the Ankang east section in the upper reaches of the Hanjiang River

\section{5 讨论与结论}

沿河谷不同地貌位置分布的古洪水滞流沉积物, 是古洪水事件的地质记录, 也是古洪水水文学研究的基 本依据. 在对汉江上游进行了深人广泛的野外考察研究后, 在安康东段河谷发现晚冰期和全新世沉积剖面, 从 中鉴别出两组古洪水滞流沉积层. LSC-A 剖面所记录的古洪水滞流沉积物 (SWD1) 夹在马兰黄土层之中 (图 
3), 由于马兰黄土 L1 顶界在 11500 a B. P. 左右, 且根据沿汉江上游多个地点地层对比分析, 认为该期古洪 水发生在 20600-11500 a B. P. 的某一时段 ${ }^{[21]}$, 且结合 SWD1 的 OSL 年龄 13150-12270 a, 认为 SWD1 记录 的古洪水事件发生在晚冰期 BL + AL 向着 YD 突变转折的阶段. 该阶段国际公认年代为 12500 a B. P. 此时 的全球性气候突变, 致使汉江上游发生暴雨洪水事件. 在贵州荔波董歌洞 D4 石笋记录 YD(新仙女木) 事件 得到明显的揭示, 其开始的时间为 12800 a B. P. , 结束于 11580 a B. P. , 降温幅度较大. $15000-11300$ a B. P. 为末次冰盛期过后急速变暖而后又回返变冷的第一个旋回 ${ }^{[35]}$. 从约 12900 a B. P. 开始, 长白山西麓哈尼泥 炭层和南极冰芯 GISP2 当中的 $\delta^{18} \mathrm{O}$ 值都突然明显减小, 指示末次冰消期中最著名的变冷事件一 $\mathrm{YD}$ 事件

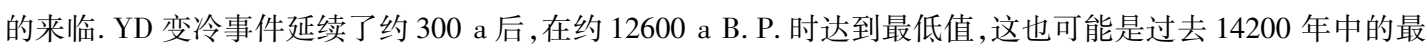
冷值. 在这之后, 长白山西麓哈尼泥炭层和南极冰芯 GISP2 当中的 $\delta^{18} \mathrm{O}$ 值都逐渐增加, 在约 12000 a B. P. 时达 到一个峰值. 长白山西麓哈尼泥炭层 $\delta^{18} \mathrm{O}$ 记录表明, 继 $\mathrm{YD}$ 事件结束, $\delta^{18} \mathrm{O}$ 突然短暂地增大后, $\delta^{18} \mathrm{O}$ 再次突 然减小 ${ }^{[36]}$. 青海湖 16000 a 以来的花粉记录显示, 13000-10400 a B. P. 气候总体特征为温凉偏湿, 但波动较 明显, 期间经历了两次相对的冷暖交替, 两次暖期出现的时段为 $13000-12000$ 和 $11600-11000$ a B. P. 之 间, 分别相当于欧洲的博令 (Bolling) 暖期和阿勒罗得 (Allerod) 暖期; 两次冷期出现的时段为 12000-11600 和 11000-10400 a B. P., 分别相当于欧洲的中仙女木期 (older dryas) 和新仙女木期 ${ }^{[37]}$. 在汉江上游南部神 农架地区大九湖的狍粉记录, 也表明该区域晚冰期及其向全新世过度时期气候冷暖波动频繁 ${ }^{[30]}$, 故而容易 引发暴雨洪水灾害. 在对南太平洋岛屿的珊瑚研究中发现, ${ }^{14} \mathrm{C}$ 在 12300 a B. P. 左右开始出现大幅度减少, 这 与从北半球记录中观察到的 $\mathrm{YD}$ 气候事件几乎是一致的 ${ }^{[38]}$. 从树木年轮和珊瑚记录的 ${ }^{14} \mathrm{C}$ 在新仙女木开始 时大量增加,而后在 12200 a B. P. 的间断期有大的波动,此波动与 ${ }^{14} \mathrm{C}$ 记录的 “老仙女木” 冷事件吻合 ${ }^{[39]}$. 所 以在世界各地,结合石笋、泥炭、狍粉、冰芯等高分辨率研究结果, 都可以证明晚冰期 BL + AL 向着 YD 转折 时是一个气候严重恶化转折期,此时气候异常波动不稳定,容易发生洪水灾害.

在安康东段 SWD2 出现在发育良好的现代表土层底部. 根据 OSL 测年技术确定其所记录的古洪水事件 发生在 $1000 \sim 900 \mathrm{a}(1000-1100 \mathrm{AD})$, 即北宋后期, 此时气候状态很不稳定, 容易产生严重的干旱和暴雨洪 水灾害. 北宋初年到南宋中叶的 $100 \mathrm{a}$ 出现了第一次明显的降温; 南宋中叶到元朝初年 $(1200-1300$ AD) 有 一个短暂的回暖期 ${ }^{[40]}$. 在对北宋的历史研究中发现,在整个北宋的 $168 \mathrm{a}$ 中, 以 20 或者 $40 \mathrm{a}$ 为时间单位来 统计和分析, 皆可发现北宋时期气候极不稳定, 暖、冷周期的交替变化表现得相当明显 ${ }^{[31]}$. 通过对荔波董哥 洞石笋进行的高精度测年和碳、氧同位素分析, 发现 1080-680 a B. P. 为降温期,气温再次下降,显示东亚冬 季风再次增强, 但降水相对增大, 表现为寒冷湿润的气候期, 是气候变化的关键转折时期 ${ }^{[41]}$. 对近 $2600 \mathrm{a}$ 来 内蒙古居延海湖泊沉积物研究发现, 1600-650 a B. P. 期间气候暖湿, 中间的冷暖波动变化很明显, 反映为 暖干一冷湿交替 ${ }^{[42]}$. 青藏高原黄龙洞石笋 HL021 的 $\delta^{18} \mathrm{O}$ 值, 在 826-1550 AD 振荡, 由负值阶段逐渐偏正, 表 明季风在此期间很不稳定, 变率较大, 故而导致气候不稳定. 万象洞石笋 WX42 $\delta^{18} \mathrm{O}$ 值记录显示在 $800-$ $1100 \mathrm{AD}$ 之间存在着几次大的波动, 气候变化不稳定. 陇南万象洞石笋和印度 Dandak 洞的石笋记录一致反 映了在中世纪暖期初期 $(950-1150 \mathrm{AD})$ 气候很不稳定, 石笋 $\delta^{18} \mathrm{O}$ 值的变化呈现处于先变轻后加重的一个 类似正弦曲线的变化, 表明当时亚洲季风和降水存在很大的波动 ${ }^{[43]}$. 北美大平原和中西部地区的多个湖泊 记录显示, 1000-1300 AD 左右该区域严重干旱事件高度频发, 同时美国西南部也多次记录到这一时期的特 大洪水事件 ${ }^{[44]}$. 对墨西哥尤卡坦半岛的内流湖研究发现, 800-1000AD 是一个气候恶化期,这一气候恶化期 正对应于古代玛雅文明的衰落 ${ }^{[45]}$. 所以 $1000 \sim 900 \mathrm{a}(1000-1100 \mathrm{AD})$, 此时冷暖波动频繁, 气候状态很不 稳定,容易产生严重的干旱和暴雨洪水灾害.

实验室对沉积样品的分析测试,进一步确定了我们在野外考察中对古洪水沉积物性质的观察判断. 粒 度成分特征是鉴别古洪水滞流沉积物的重要标志. 河流古洪水滞流沉积物是在接近静水环境下由悬移质沉 积形成. 所以通过对安康东段古洪水 SWD 的沉积学分析, 证明它们是最典型的古洪水滞流沉积物, 以粗粉 砂或者细砂为主, 细粉砂和黏土含量很低. 其在沉积学分类上确定为粉砂质细砂、细砂质粉砂. 其粒度分布 集中, 分选较好, 磁化率值较低,与 2010 年现代洪水滞流沉积物相同.

结合汉江上游峡谷河槽特点, 根据两期古洪水滞流沉积层的尖灭点高程, 确定了安康东段两个断面的 古洪水洪峰水位. 结合野外测量和观察获得的相关水文参数, 利用面积一比降法模型, 推算出汉江上游万年 
尺度古洪水的洪峰流量介于 $35970 \sim 47400 \mathrm{~m}^{3} / \mathrm{s}$ 之间. 同时, 根据调查确定的 2010 年特大洪水的洪痕水位, 采用同样的方法和参数恢复计算出其洪峰流量, 与安康水文站实测数据误差仅为 $4.52 \%$. 从而证明我们对 汉江上游峡谷古洪水洪峰流量计算的方法是合理的,计算结果是可靠的.

依据本文从沉积学角度推算出的古洪水洪峰流量数据, 结合历史洪水调查结果和实测洪水序列, 采用 含有特大值的不完整序列频率计算方法, 作出了汉江上游安康东段万年尺度洪峰流量与频率关系. 这就为 汉江上游的水利水电、交通工程建设提供了重要的基础数据, 同时,对于揭示汉江上游全新世气候变化和水 文变化及其对全球变化的响应规律具有重要的科学意义.

在以后的研究中我们还将继续调查寻找完整连续的全新世沉积物剖面, 识别汉江古洪水 SWD 沉积物, 结合 OSL 测年断代, 准确地揭示汉江上游全新世气候变化和水文变化的规律, 为揭示全球变化的区域性影 响提供依据.

致谢: 感谢庞奖励、查小春、周亚利等老师在野外考察中的指导以及周亮在 OSL 测年中的帮助.

\section{6 参考文献}

[1] 谢悦波,姜红涛. 古洪水研究: 挖掘河流大洪水的编年史. 南京大学学报:自然科学版,2001,37(3):390-395.

[ 2 ] Sridhar A. A mid-late Holocene flood record from the alluvial reach of the Mahi River, Western India. Catena, 2007, 70: 330-339.

[ 3 ] Gerardo B, Sopcña A, Sánchez-Moya Y et al. Palaeoflood record of the Tagus River( Central Spain) during the Late Pleistocene and Holocene. Quaternary Science Reviews, 2003, 22 : 1737-1756.

[ 4 ] Baker VR. Palaeoflood hydrology in a global context. Catena, 2006, 66: 161-168.

[ 5 ] 谢悦波,费宇红,沈起鹏. 古洪水平流沉积与水位. 地球学报,2001,22(4) : 320-323.

[ 6 ] Benito G, Thorndycraft VR, Rico M et al. Palaeoflood and floodplain records from Spain: Evidence for long-term climate variability and environmental changes. Geomorphology, 2008, 101: 68-77.

[ 7 ] 谢悦波,杨达源. 古洪水平流沉积基本特征. 河海大学学报,1998,26(6):6-11.

[8] 谢悦波,张素亭,毕东生.古洪水行洪断面面积的估算.河海大学学报,1999,27(5):8-11.

[ 9 ] 谢悦波,王文辉,王 平. 古洪水平流沉积粒度特征. 水文,2000,20(4):18-20.

[10] 詹道江,谢悦波. 古洪水研究. 北京: 中国水利水电出版社,2001:1-83.

[11] Huang CC, Pang JL, Zha XC et al. Extraordinary floods of $4100-4000$ a BP recorded at the Late Neolithic ruins in the Jinghe River gorges, middle reach of the Yellow River, China. Palaeogeography, Palaeoclimatology, Palaeoecology, $2010,289(3): 1-9$.

[12] Huang CC, Jia YF, Pang JL et al. Holocene colluviation and its implications for tracing human-inducesoil erosion and redeposition on the piedmont loess lands of the Qinling Mountains, northern China. Geoderma, 2001, 36 : 838-851.

[13] Huang CC, Pang JL, Zha XC et al. Extraordinary floods related to the climatic event at 4200 a BP on the Qishuihe River, middle reaches of the Yellow River, China. Quaternary Science Reviews, 2011, 30: 460-468.

[14] 万红莲,黄春长, 庞奖励等. 渭河宝鸡峡全新世特大洪水水文学研究. 第四纪研究, 2010,30(2):430-440.

[15] 葛本伟,黄春长,周亚利等. 龙山文化末期泾河特大洪水事件光释光测年研究. 第四纪研究, 2010,30(2):422-429.

[16] 李晓刚,黄春长,庞奖励等. 黄河壶口段全新世古洪水事件及其水文学研究. 地理学报,2010,65(11):1371-1380.

[17] 黄春长, 庞奖励, 周亚利等. 黄河流域关中盆地史前大洪水研究——以周原漆水河谷地为例. 中国科学: 地球科学, $2011, \mathbf{4 1}(11): 1658-1669$.

[18］李幼木. 汉江安康流域洪水规律分析及水库对安康城区的防洪作用. 陕西电力, 2007,35(10):37-40.

[19］雷祥义,岳乐平,王建琪等. 秦岭凤州黄土磁学特征及其古气候意义. 科学通报, 1998,43(14) : 1537-1540.

[20] LuHY, Zhang HY, Wang SJ et al. Multiphase timing of hominin occupations and the paleoenvironment in Luonan Basin, Central China. Quaternary Research, 2011,76:142-147.

[21] 庞奖励, 黄春长, 周亚利等. 汉江上游谷地全新世风成黄土及其成壤改造特征. 地理学报,2011,66(11):1562-1573.

[22] 刘东生.黄土与环境. 北京:科学出版社, 1985 :62-81.

[23] 任明达,王乃梁. 现代沉积环境概论. 北京:科学出版社, 1981:8-26.

[24] An ZS, Kukla GJ, Porter SC. Magnetic susceptibility evidence of monsoon variation on the Loess Plateau of central China during the last 130,000 years. Quaternary Research, 1991, 36(1) : 29-36. 
[25] 刘秀铭,刘东生, Heller F 等. 中国黄土磁化率与第四纪古气候研究. 地质科学 (增刊), 1992,12:279-285.

[26] 刘秀铭,刘东生,Shaw J 等. 中国黄土磁性矿物特征及其古气候意义. 第四纪研究, 1993,13 (3) :281-287.

[27］鹿化显,安芷生. 洛川黄土记录的最近 $2500 \mathrm{ka}$ 东亚冬夏季风变化周期. 地质评论, 1998,44 (5):553-558.

[28］鹿化显,安芷生. 洛川黄土粒度组成的古气候意义. 科学通报, 1997,42(1):66-69.

[29] 黄春长. 环境变迁. 北京:科学出版社, 1998:15-200.

[30] 朱 诚, 马春梅, 张文卿等. 神农架大九湖 $15.753 \mathrm{kaB}$. P. 以来的狍粉记录和环境演变. 第四纪研究, 2006, 26 (5): 814-826.

[31］张全明. 论北宋开封地区的气候变迁及其特点. 史学月刊,2007,(1):98-108.

[32］史辅成,易元俊,慕 平. 黄河历史洪水调查、考证和研究. 郑州: 黄河水利出版社,2002:81-123.

[33] McManus J. Grain size determination and interpretation. In:Tucker M ed. Techniques in sedimentology. Oxford: Blackwell, 1988: 63-85.

[34] 武汉水利电力学院水力学教研室. 水力学. 北京: 高等教育出版社, 1986:335-336.

[35] 覃嘉铭,袁道光, 程 海等. 新仙女木及全新世早中期气候突变事件:贵州茂兰石笋氧同位素记录. 中国科学: D 辑: 地球科学, 2004,34(1):69-74.

[36] 洪 冰,刘丛强,林庆华等. 哈尼泥炭 $\delta^{18} O$ 记录的过去 14000 年温度演变. 中国科学, 2009,39(5):626-637.

[37] 刘兴起, 沈 吉, 王苏民等. 青海湖 16ka 以来的花粉记录及其古气候古环境演化. 科学通报, 2002,47(17): 1351-1355.

[38 ] Donahue DJ. Radiocarbon analysis by accelerator mass spectrometry. International Journal of Mass Spectrometry and Ion Processes, 1995, 143: 235-245.

[39] Jull AJT, Burr GS, McHargue LR et al. New frontiers in dating of geological, paleoclimatic andanthropological applications using accelerator massspectrometric measurements of ${ }^{14} \mathrm{C}$ and ${ }^{10} \mathrm{Be}$ in diverse samples. Global and Planetary Change, 2004, 41 : 309-323.

[40］王会昌. 2000 年来中国北方游牧民族南迁与气候变化. 地理科学, 1996,16(8):274-279.

[41］张美良,程 海,林玉石等. 贵州荔波地区 2000 年来石笋高分辨率的气候记录. 沉积学报,2006,24(3):339-348.

[42］篗文川,吴瑞金,王苏民等. 近 2600 年来内蒙古居延海湖泊沉积物的色素含量及环境意义. 沉积学报, 2000,18 (1) : 13-17.

[43] 杨勋林. 青藏高原东部近 1200 年来高分辨率洞穴石笋 $\delta^{18} \mathrm{O}$ 记录 [ 学位论文]. 兰州: 兰州大学,2007.

[44] Laird KR, Fritz SC, Cumming BF. A diatom-based reconstruction of drought intensity, duration, and frequency from Moon Lake, North Dakota: a sub-decadal record of the last 2300 years. Journal of Paleolimnology, 1998, 19: 161-179.

[45] Hodell DA, Curtis JH, Brenner M et al. Possible role of climate in the collapse of Classic Maya civilization. Nature, 1995, 375: 391-394. 